Cite this as: $B M / 2020 ; 371: \mathrm{m} 4269$ http://dx.doi.org/10.1136/bmj.m4269 Published: 09 November 2020

\section{Food and mood: how do diet and nutrition affect mental wellbeing?}

The surname of Alessandra Borsini was misspelt in the author list of this article by Joseph Firth and colleagues (BMJ 2020;369:m2382, doi:). The online version has been corrected. 